\title{
Moving Fingers Associated with Dupuytren's Disease: A Case Report
}

\author{
Spiridon Papapetropoulos ${ }^{\mathrm{a}} \quad$ Abraham Rapoport $^{\mathrm{b}}$ Ronit Guilad ${ }^{\mathrm{b}} \quad$ Anda Eilam $^{\mathrm{b}}$ \\ Yair Lampel $^{\mathrm{b}}$ Carlos Singer ${ }^{\mathrm{a}}$ Menachem Sadeh $^{\mathrm{b}}$ \\ ${ }^{a}$ Department of Neurology, University of Miami, Miller School of Medicine, Miami, Fla., USA; ${ }^{b}$ Department of \\ Neurology, Wolfson Medical Center, Holon Sackler Faculty of Medicine, Tel Aviv University, Tel Aviv, Israel
}

Dear Sir,

The association of deep pain sensation and erratic extremity movements has been well described in many cases of painful leg and moving toes [1]. Painless arms/moving fingers (MF) is a rare variant of the painful limbs/moving extremities syndrome characterized by slow involuntary movements of the fingers in the absence of pain [2]. Only a few MF cases have been reported [2-5]. Although the etiology of painful limbs/moving extremities remains unclear, several precipitating factors including central nervous system insults, peripheral tissue, nerve or root injury, or peripheral neuropathy have been identified [6]. In their majority MF cases are bilateral. We report a unique case of unilateral MF associated with peripheral tissue pathology (Dupuytren's contracture) and no other apparent etiology.

\section{Case Report}

A 70-year-old, right-handed man was first evaluated for right-hand involuntary finger movements of 4-year duration in the setting of Dupuytren's disease. The movement disorder appeared gradually shortly after (about 20 months) the patient had been diagnosed as having Dupuytren's disease. Involuntary movements disappeared with voluntary contractions of right hand muscles only to reappear during relaxation. They remained strictly uni- lateral and were never accompanied or preceded by painful or unpleasant sensation. Medical history was remarkable for breast cancer at the age of 45 , with no adjuvant treatment, such as chemotherapy or radiotherapy. The patient also had bilateral hip replacement at the age of 40 , bilateral cataract surgery at the age of 60 and transurethral prostatectomy for benign prostatic hypertrophy at the age of 65 . Brain magnetic resonance imaging only revealed symmetric periventricular ischemic lesions. Upper limb electrophysiological nerve conduction studies showed a very mild axonal sensory-motor peripheral symmetric polyneuropathy.

General physical examination was unremarkable except for Dupuytren's contracture (see fig. 1). Neurological examination revealed almost continuous, painless, brief contractions of small amplitude mostly in the area of flexion and extension at the metacarpal-phalangeal and interphalangeal joints of all the fingers of the right hand (on relaxation). The movements were irregular and asynchronous. Although contractures caused hand deformity, the involuntary movements were easily noticeable. The flexion component was more prominent than the extension movement, probably due to limitations of extension caused by the contractures. An occasional very mild movement of abduc- tion-adduction of the 2nd and 3rd fingers was also noted. The irregular movements are presented in the second segment of the video (online suppl. videos, www.karger. com/doi/10.1159/000109578). No other extrapyramidal features were noted. The remainder of the neurological exam was noncontributory. Due to the mild nature of the symptoms and no major inhibition of everyday activities, no form of treatment was administered. During a 2-year follow-up period the patient reported no deterioration of his involuntary movements or his contractures associated with Dupuytren's disease.

\section{Discussion}

In 1971, Spillaine et al. [1] described 6 patients with a peculiar set of symptoms that they named 'painful legs and moving toes'. This syndrome was characterized by spontaneous causalgia accompanied by involuntary movements of the toes.

Since then painful limbs/moving extremities has been identified as a syndrome with many variants (painless [7], unilateral [8], involving only arms [4], only legs [1] or both [8]).

Painful limbs/moving extremities can be idiopathic or associated with central and/or peripheral nervous system conditions [6]. Peripheral nerves (injury or neuropathy), posterior root ganglia (herpes

\section{KARGER}

Fax +41613061234 E-Mail karger@karger.ch www.karger.com
Spiridon Papapetropoulos, MD, $\mathrm{PhD}$

Department of Neurology, University of Miami, Miller School of Medicine

1501 NW 9th Avenue (NPF), Room 4004

Miami, FL 33136 (USA)

Tel. +1 305243 8461, Fax +1 305243 3321, E-Mail spapapetropoulos@med.miami.edu 
Fig. 1. The affected right limb with Dupuytren's disease is shown. Contracture of the palmar fascia resulted in hand deformities and was associated with the appearance of painless involuntary finger movements.

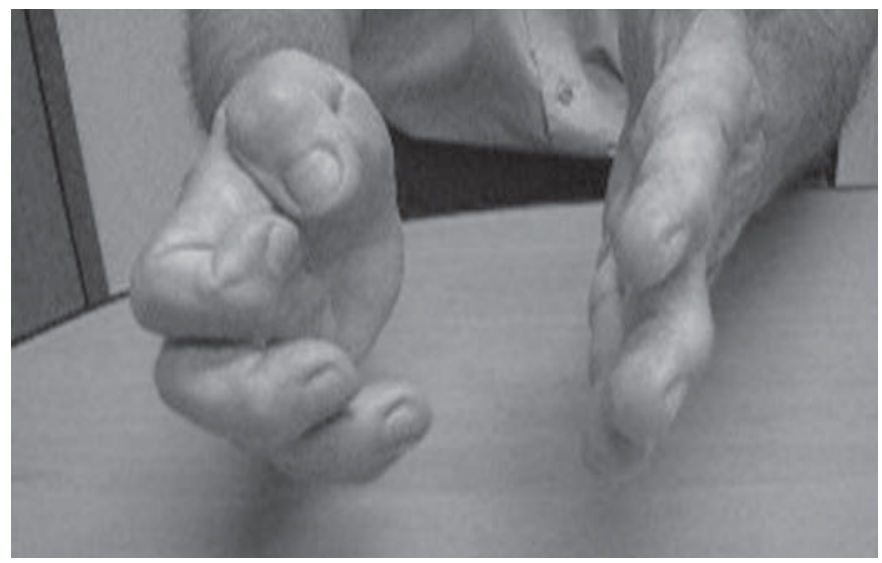

zoster), spinal root injury (spinal column and disc abnormalities), spinal cord and basal ganglia have been topographically associated with painful limbs/moving extremities [9]. The role of peripheral tissue damage was discussed by Nathan [10], who described onset of the syndrome following a deep laceration to the foot. Schott [11] and Dressler et al. [6] described 3 cases of painful legs and moving toes that developed in patients after foot surgery. These cases of trauma, however, do little to clarify the etiology, since they also involved significant central or peripheral nervous system pathology [9].

In our case a painless variant of painful limbs/moving extremities is associated with Dupuytren's disease. Although a casual relationship cannot be totally excluded, the temporal course of the disease and its unilateral nature considerably strengthen the association with Dupuytren's disease. On the other hand the absence of bilateral symptoms in the presence of mild bilateral symmetric polyneuropathy makes the association with peripheral neuropathy unlikely. Dupuytren's disease is a widespread benign fibroproliferative disorder of the palmar fascia that often results in disfigurement of hands and fingers with different degrees of functional impact. Most patients suffering from Dupuytren's disease are native to or descendants from northern Europe, where approximately $10 \%$ of the male population older than 65 years is affected [12]. Many etiological factors have been suggested as candidates responsible for individual development of Dupuytren's disease, e.g. alcoholism [13], smoking [14], diabetes mellitus [15], trauma [16] and genetic predisposition [17].
A common hypothesis in painfullimbs/ moving extremities cases associated with peripheral tissue damage implies that involuntary movements are caused by alterations in afferent sensory information with subsequent reorganization of segmental or suprasegmental efferent motor activity [6]. This theory shares similarities with that of the development of dystonia secondary to peripheral trauma ('peripheral dystonia') and may explain the occasional association of painful limbs/moving extremities with focal limb dystonia $[2,4]$ and response of painful limbs/moving extremities to botulinum toxin injections [2].

In summary we present a first case of MF associated with peripheral tissue damage caused by Dupuytren's disease. Painful limbs/moving extremities is a disorder with many variants and a multifactorial etiology. More research into its pathogenesis is warranted.

\section{Acknowledgment}

We are grateful to Ms Avivah Peld and Dr. Vitali Finkelshtein for their help in the preparation of the manuscript.

\section{References}

1 Spillane JD, Nathan PW, Kelly RE, Marsden $\mathrm{CD}$ : Painful legs and moving toes. Brain 1971;94:541-556.

2 Singer C, Papapetropoulos S: A case of painless arms/moving fingers responsive to botulinum toxin a injections. Parkinsonism Relat Disord 2007;13:55-56.

3 Funakawa I, Mano Y, Takayanagi T: Painful hand and moving fingers: a case report. J Neurol 1987;234:342-343.

4 Supiot F, Gazagnes MD, Blecic SA, Zegers de Beyl D: Painful arm and moving fingers: clinical features of four new cases. Mov Disord 2002;17:616-618.
5 Verhagen WI, Horstink MW, Notermans SL: Painful arm and moving fingers. J Neurol Neurosurg Psychiatry 1985;48:384-385.

6 Dressler D, Thompson PD, Gledhill RF, Marsden CD: The syndrome of painful legs and moving toes. Mov Disord 1994;9:13-21.

7 Dziewas R, Kuhlenbaumer G, Okegwo A, Ludemann P: Painless legs and moving toes in a mother and her daughter. Mov Disord 2003; 18:718-722.

8 Ebersbach G, Schelosky L, Schenkel A, Scholz U, Poewe W: Unilateral painful legs and moving toes syndrome with moving fingers - evidence for distinct oscillators. Mov Disord 1998;13:965-968.

9 Yoon J, Crabtree C, Botek G: Syndrome of painful legs and moving toes: a case study. J Am Podiatr Med Assoc 2001;91:361-364.

10 Nathan PW: Painful legs and moving toes: evidence on the site of the lesion. J Neurol Neurosurg Psychiatry 1978;41:934-939.

11 Schott GD: 'Painful legs and moving toes': the role of trauma. J Neurol Neurosurg Psychiatry 1981;44:344-346.

12 McFarlane RM: On the origin and spread of Dupuytren's disease. J Hand Surg (Am) 2002; 27:385-390.

13 Bradlow A, Mowat AG: Dupuytren's contracture and alcohol. Ann Rheum Dis 1986; 45:304-307.

14 An HS, Southworth SR, Jackson WT, Russ B: Cigarette smoking and Dupuytren's contracture of the hand. J Hand Surg (Am) 1988;13: 872-874.

15 Ross DC: Epidemiology of Dupuytren's disease. Hand Clin 1999;15:53-62, vi.

16 Hueston JT: Dupuytren's contracture and specific injury. Med J Aust 1968;1:1084-1085.

17 Burge P: Genetics of Dupuytren's disease. Hand Clin 1999;15:63-71. 